\author{
Jurnal E-Bis (Ekonomi-Bisnis) \\ Vol. 5 No.2 (2021) pp. 553-560 \\ https://jurnal.politeknik-kebumen.ac.id/index.php/E-Bis \\ p-ISSN : 2580-2062 e-ISSN : 2622-3368
}

\title{
Determinan Niat beli pada Customer Geprek BENSU: Peran E-Wom, Celebrity Endorser dan Customer Attitude
}

\author{
Ika Susilowati \\ Manajemen Pemasaran, Universitas Putra Bangsa, Indonesia \\ *Email : ikasusilowatistiepb@gmail.com \\ Doi : https://doi.org/10.37339/e-bis.v5i2.554
}

Diterbitkan oleh Politeknik Dharma Patria Kebumen

Info Artikel

Diterima :

2021-04-17

Diperbaiki :

2021-10-11

Disetujui :

2021-10-25

\begin{abstract}
ABSTRAK
Tujuan penelitian ini adalah untuk mengetahui dan menguji pengaruh E-wom dan celebrity endorser terhadap niat beli melalui sikap pelanggan sebagai variabel intervening pada pelanggan Geprek BEBSU. Survei dilakukan dengan melibatkan 100 responden. Penelitian ini merupakan penelitian kuantitatif. Hasil penelitian ini menunjukkan bahwa e-wom dan celebrity endorser memiliki pengaruh yang signifikan dan positif terhadap sikap dan niat beli pelanggan. Namun, sikap pelanggan tidak berpengaruh positif terhadap niat beli. Sikap pelanggan sebagai variabel intervening juga tidak berpengaruh positif pada variabel e-wom dan celebrity endorser terhadap niat beli.
\end{abstract}

Kata Kunci: E-wom, Celebrity Endorser, Customer Attitude, Niat Beli

\begin{abstract}
The purpose of this study was to determine and examine the effect of E-wom and celebrity endorser on purchase intention through customer attitude as an intervening variable on Geprek BEBSU customers. The survey was conducted by involving 100 responden. This research is a quantitative research. The results of this study indicate that e-wom and celebrity endorsers have a significant and positive influence on customer attitudes and purchase intentions. However, customer attitude does not have a positive effect on purchase intention. Customer attitude as an intervening variable also does not have a positive effect on the e-wom and celebrity endorser variables on purchase intention.
\end{abstract}

Keywords: E-wom, Celebrity Endorser, Consumer Attitude, and Purchase Intention 


\section{PENDAHULUAN}

Kemajuan industri dan teknologi saat ini membuat Indonesia berkembang sangat pesat. Kondisi ini mengharuskan perusahaan untuk kreatif dan inovatif dalam menjalankan bisnisnya dan selalu berfikir bagaimana cara untuk mendapatkan yang terbaik guna memperoleh dan mempertahankan pangsa pasar. Sehingga, diperlukan suatu strategi bisnis untuk mendapatkan kinerja bisnis yang baik. Alat yang digunakan suatu perusahaan untuk menarik niat beli customer adalah dengan bauran pemasaran.

Niat beli merupakan sikap ketertarikan customer terhadap produk atau jasa yang sesuai dengan kriteria kebutuhan customer. Sehingga customer cenderung membeli suatu produk dengan mengukur tingkat kemungkinan customer melakukan pembelian (Swastha \& Handoko, 2000). Niat beli disebut juga dengan elemen konatif pada sikap yang berkaitan dengan kemungkinan suatu customer untuk membeli produk (Schiffman et al., 2015) Niat beli merupakan tahapan yang mengarah pada keputusan pembelian (Shafiq et al., 2011). Niat beli di pengaruhi oleh e-wom (Tariq et al., 2017; Yunus et al., 2016; Bataineh 2015; East et al., 2008), celebrity endorser (Asmai, 2011; Nelson, 2012) dan customer attitude (Zu Qian et al., 2015).

East (2008) menyatakan bahwa yang berpengaruh dalam hal pengambilan keputusan pada suatu produk adalah saran dari orang yang sudah mengenal produk tersebut sebelumnya. Tariq et al (2017) menyatakan bahwa E-WOM customer mampu mengumpulkan informasi tentang produk dan jasa yang akan dibeli. Customer mengumpulkan informasi melalui orang yang dikenal dan dari orang lain yang sudah pernah memakai produk atau jasa tersebut sehingga mendorong customer dalam niat beli. Pernyataan ini di dukung oleh penelitian Yunus, et al (2016) dan Bataineh (2015). Namun Torlak, et al (2014) dalam penelitiannya menyatakan EWOM tidak berpengaruh signifikan terhadap niat beli yang disebabkan oleh sampel penelitian.

Selain e-wom, celebrity endorser merupakan faktor lain yang mempengaruhi niat beli. Asmai (2008) menyatakan bahwa penggunaan celebrity sebagai pengiklan terbukti sangat efektif dalam pengiklanan beberapa produk. Nelson (2012) menyatakan dukungan celebrity endorser telah memberikan sentuhan dan menciptakan daya tarik tambahan bagi customer. Deswindi (2007) menyatakan bahwa hal yang paling banyak memengaruhi customer dalam memutuskan pembelian suatu produk adalah rangsangan marketing. Rangsangan marketing yang dimaksud adalah product, price, place dan promotion. Pemilihan celebrity endorser diharapkan dapat membantu menarik customer dan meningkatkan jumlah penjualan dari produk tersebut.

Hasil penelitian Jalilvand (2011) menyatakan bahwa pengaruh e-wom terhadap niat beli tidak terjadi dengan sendirinya, melainkan customer attitude. Reham et al., (2016) dalam penelitiannya menyatakan bahwa customer lebih banyak berperan dalam e-wom saat membeli suatu produk. Pernyataan ini didukung oleh penelitian Methaq (2012) dan Muda et al., (2014).

Stephanie et al., (2013) dalam penelitiannya menyatakan bahwa celebrity endorse tidak berpengaruh secara langsung pada variable niat beli, melainkan terlebih dahulu melalui variable sikap. Maka dalam penelitian ini, peneliti menambahkan customer attitude sebagai variabel intervening.

Customer attitude merupakan faktor penting yang mempengaruhi niat membeli customer. sikap adalah tendensi dalam berperilaku yang menyenangkan atau tidak terhadap obyek tertentu (Schiffman dan Kanuk, 2010). Maka, customer attitude terhadap e-wom maupun celebrity endoser akan berpengaruh terhadap niat beli. Geprek bensu merupakan makanan cepat saji yang 
didirikan pada tanggal 17 April 2017. Berdasarkan telaah literatur, penulis akan melakukan penelitian tentang pengaruh e-wom dan celebrity endorser terhadap niat beli dengan customer attitude sebagai variabel interveing pada customer geprek BENSU.

\section{KAJIAN PUSTAKA}

\subsection{E-Wom}

Elektronic-word-ofmouth merupakan gabungan dari komunikasi word-ofmouth dari lingkungan offline ke online. Masih banyak referensi mengeksplorasi word-ofmouth dalam masa pengirim dan penerima masih mengacu pada pendapat dan masih mencari pendapat perspektif lainnya (Sun et al, 2009.

\subsection{Celebrity Endoser}

Celebrity endorser merupakan salah satu strategi promosi yang sudah digunakan oleh banyak perusahaan. Dengan menggunakan celebrity endoser yang sesuai dengan karakteristik diyakini mampu meningkatkan penjualan produk dari perusahaan. Perusahaan bekerjasama dengan celebrity untuk memakai produknya bertujuan agar pesan yang ingin disampaikan perusahaan dapat tersampaikan dengan baik kepada customer.

\subsection{Customer Attitude}

Customer attitude adalah tindakan individu terhadap suatu obyek melalui sikap, jadi dapat dikatakan bahwa attitude terhadap produk merupakan tindakan seseorang terhadap produk yang memiliki komponen seperti nama produk, gambar dan symbol-simbol, karakter dalam kemasan. Melalui proses evaluasi inilah individu akan memberikan kesimpulan terhadap obyek sikap baik yang disenangi maupun yang tidak disenangi.

\subsection{Niat Beli}

Kotler dan Keller (2009:189) dalam penelitiannya menyebutkan faktor-faktor apa saja yang membentuk niat beli yang akhirnya terciptanya keputusan pembelian:

a. Sikap orang lain

Sikap orang lain mengurangi alternative produk yang disenangi. Untuk memutuskan niat beli seseorang bergantung pada dua hal yaitu sikap negatif orang lain terhadap produk yang disenangi customer dan semangat customer untuk meyakini orang lain.

b. Faktor keadaan yang tidak terantisipasi

faktor keadaan yang tidak terantisipasi yang akan mengubah pendirian seorang customer. Hal tersebut yang akhirnya membuat customer menjadi bingung, apakah customer percaya diri dalam mengambil keputusan dalam melakukan pembelian suatu barang. 


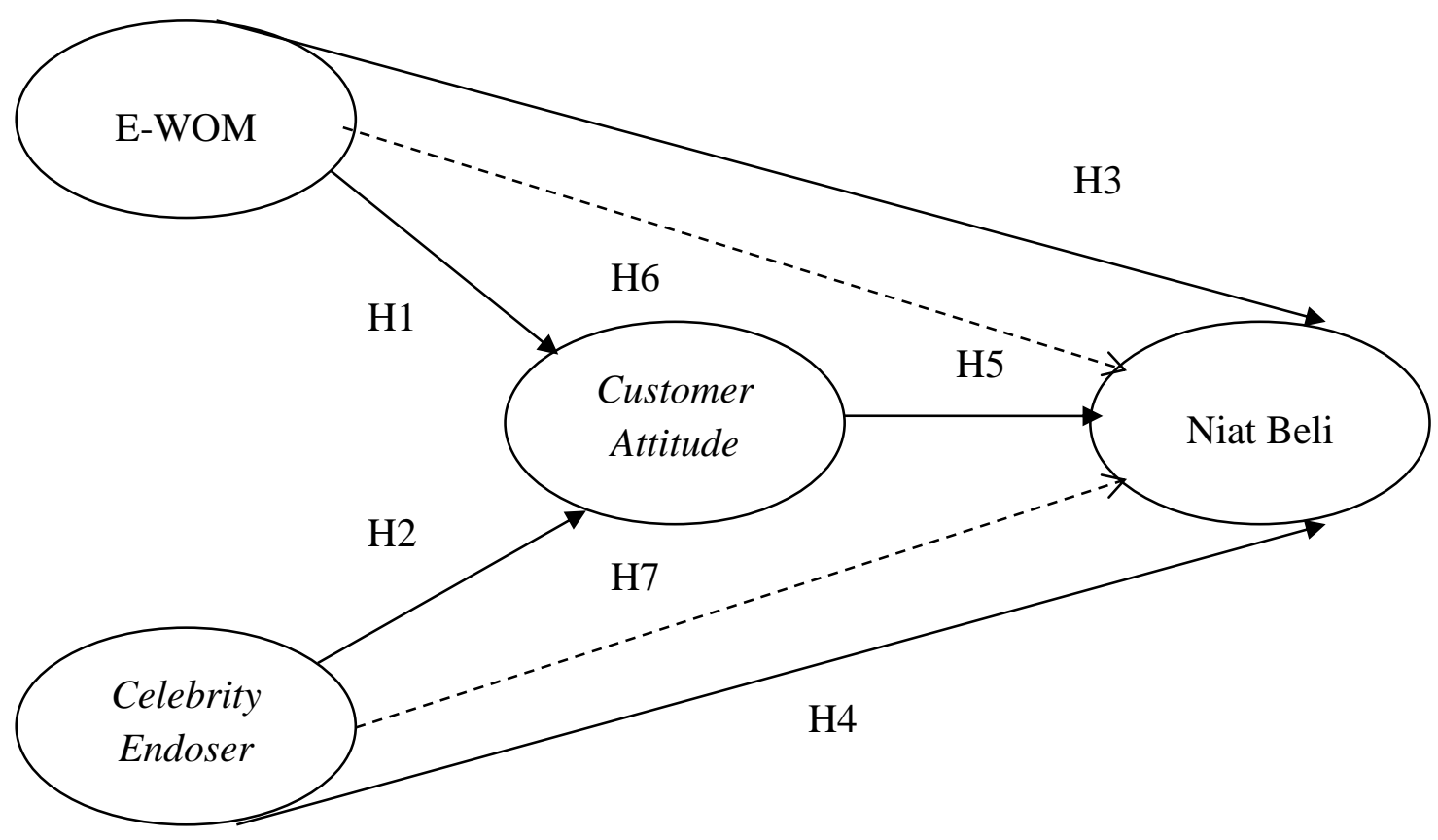

Gambar 1. Model Empiris

\subsection{Pengembangan Hipotesis}

Berdasarkan model penelitian dan hubungan antar variabel penelitian, maka penelitian ini merumuskan hipotesis sebagai berikut:

$\mathrm{H}_{1}$ : E-WOM berpengaruh signifikan terhadap customer attitude

$\mathrm{H}_{2}$ : Celebrity endorser berpengaruh signifikan terhadap customer attitude

$\mathrm{H}_{3}$ : E-WOM berpengaruh signifikan terhadap niat beli

$\mathrm{H}_{4}$ : Celebrity endorser berpengaruh signifikan terhadap niat beli

$\mathrm{H}_{5}$ : Customer attitude berpengaruh signifikan terhadap niat beli

$\mathrm{H}_{6}$ : E-WOM berpengaruh signifikan terhadap niat beli melalui customer sttitude

$\mathrm{H}_{7}$ : Celebrity endorser berpengaruh signifikan terhadap niat beli melalui customer attitude

\section{METODE}

Penelitian ini menggunakan pengujian hipotesis dan merupakan penelitian kuantitatif yang dilakukan pada customer Geprek Bensu. Penentuan sampel dengan teknik non probalibility sampling dan menggunakan purposive sampling, dengan jumlah responden sebanyak 100 orang. Metode pengumpulan data dengan kuesioner. Data analisis yang digunakan dalam penelitian ini adalah dengan uji validitas dan uji reliabilitas, analisis jalur dan uji sobel.

\section{HASIL DAN PEMBAHASAN}

\subsection{Uji Validitas}

Tabel1. Hasil uji validitas Kuesioner 


\begin{tabular}{ccccc}
\hline Variabel & Butir & rhitung & Signifikansi & Ket \\
\hline E-WOM & Butir1 & 0,812 & 0,000 & Valid \\
& Butir2 & 0,752 & 0,000 & Valid \\
& Butir3 & 0,704 & 0,000 & Valid \\
& Butir4 & 0,702 & 0,000 & Valid \\
Celebrity Endorser & Butir5 & 0,273 & 0,000 & Valid \\
& Butir1 & 0,454 & 0,000 & Valid \\
& Butir2 & 0,890 & 0,000 & Valid \\
& Butir3 & 0,712 & 0,000 & Valid \\
Customer Attitude & Butir4 & 0,911 & 0,000 & Valid \\
& Butir5 & 0,734 & 0,000 & Valid \\
Niat Beli & Butir1 & 0,844 & 0,000 & Valid \\
& Butir2 & 0,826 & 0,000 & Valid \\
& Butir3 & 0,811 & 0,000 & Valid \\
& Butir1 & 0,725 & 0,000 & Valid \\
& Butir2 & 0,881 & 0,000 & Valid \\
\hline
\end{tabular}

Sumber: Data Primer Diolah, 2020

\subsection{Uji Reliabilitas}

Tabel2. Hasil uji reliabilitas

\begin{tabular}{lcc}
\hline \multicolumn{1}{c}{ Variabel } & R Kritis & Cronbach Alpha \\
\hline E-WOM & $\alpha>0,60$ & 0,644 \\
Celebrity Endorser & $\alpha>0,60$ & 0,810 \\
Customer Attitude & $\alpha>0,60$ & 0,768 \\
Niat Beli & $\alpha>0,60$ & 0,787 \\
\hline
\end{tabular}

Sumber: Data Primer Diolah, 2020

Berdasarkan tabel2. Dijelaskan bahwa nilai Cronbach Alpha $>\mathrm{r}_{\text {kritis }}$, sehingga instrumen dalam variable penelitin ini reliabel.

\subsection{Analisis Jalur}

Tabel 3. Hasil Pengujian

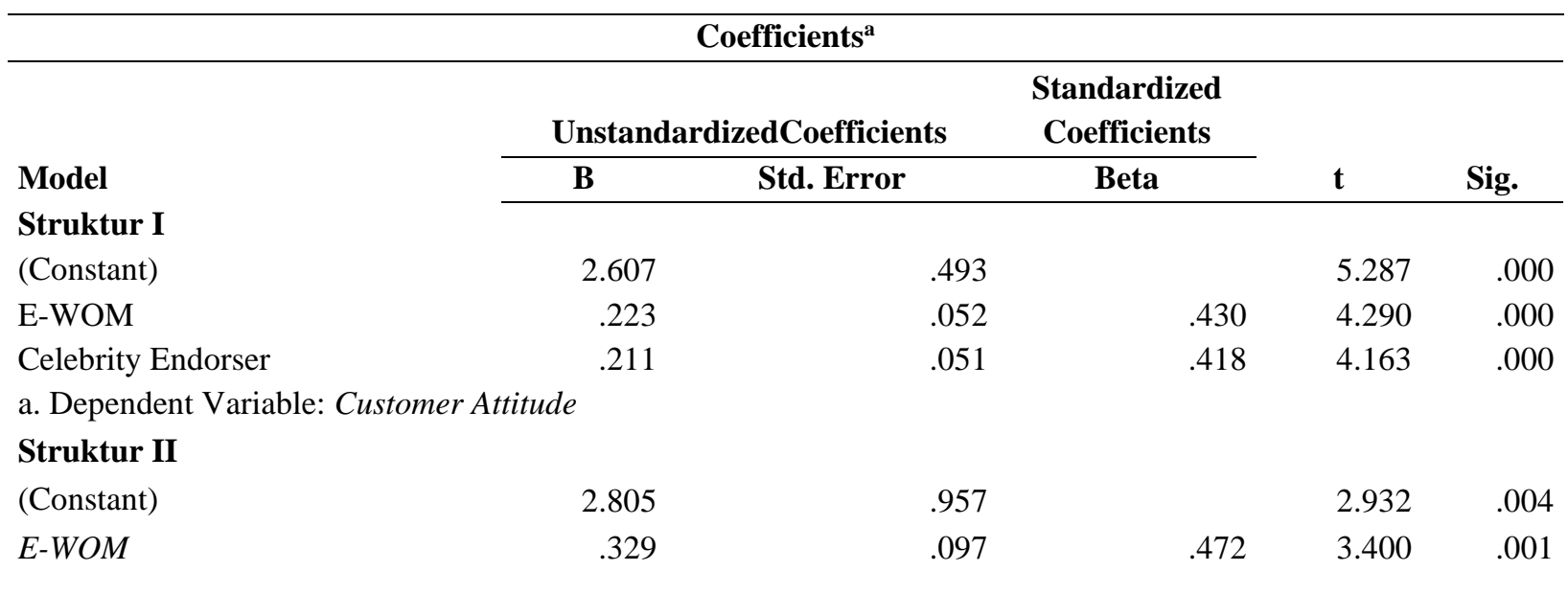




\subsection{Uji sobel}

Tabel 4. Hasil Uji Sobel Substruktural 1

\begin{tabular}{ccc}
\hline Test Statistic & Standar Eror & P-Value \\
\hline$-1,74105515$ & 0.06670495 & 0.08167391 \\
\hline
\end{tabular}

Berdasarkan tabel4. Dijelaskan bahwa test statistic $<\mathrm{t}$ tabel yaitu $-1,7410<1,9844$ dan p-value $>$ a yaitu $0,08>0,05$. Sehingga customer attitude tidak dapat memediasi antara variable E-WOM dengan variabel niat beli.

Tabel5. Hasil uji sobel substruktural 2

\begin{tabular}{ccc}
\hline Test Statistic & Standar Eror & P-Value \\
\hline-1.69858114 & 0.06068359 & 0,08939813 \\
\hline
\end{tabular}

Sumber: Data primer yang diolah, 2020

1. Pengaruh E-wom terhadap customer attitude

Hasil uji signifikasi diperoleh nilai thitung sebesar 4,290 > ttabel sebesar 1,9844 sehingga disimpulkan bahwa variable E-WOM berpengaruh secara signifikan terhadap variabel customer attitude atau dapat diartikan bahwa hipotesis (H1) diterima.

2. Pengaruh celebrity endorser terhadap customer attitude

Hasil uji signifikasi diperoleh nilai thitung sebesar 4,163 > ttabel sebesar 1,9844 sehingga disimpulkan bahwa variable celebrity endorser berpengaruh secara signifikan terhadap variabel customer attitude atau dapat diartikan bahwa hipotesis (H2) diterima

3. Pengaruh E-wom terhadap niat beli

Hasil uji signifikasi diperoleh nilai thitung sebesar 3,400 > ttabel sebesar 1,9847 sehingga disimpulkan bahwa variable E-WOM berpengaruh signifikan secara terhadap variabel niat beli atau dapat diartikan bahwa hipotesis (H3) diterima.

4. Pengaruh celebrity endorser terhadap niat beli

Hasil uji signifikasi diperoleh nilai thitung sebesar 3,105 > ttabel sebesar 1,9847 sehingga disimpulkan bahwa variable celebrity endorser berpengaruh secara signifikan terhadap variabel niat beli atau dapat diartikan bahwa hipotesis (H4) diterima.

5. Pengaruh customer attitude terhadap niat beli

Hasil uji signifikansi sebesar 0,045 < 0,05 dan hasil dari perhitungan diperoleh nilai thitung sebesar -2,035 < ttabel sebesar 1,9847 sehingga disimpulkan bahwa variable customer attitude tidak berpengaruh terhadap variable niat beli atau dapat diartikan bahwa hipotesis (H5) ditolak.

6. Pengaruh E-WOM terhadap niat beli melalui customer attitude

Berdasarkan hasil uji yang digunakan dengan kalkulator sobel menunjukan bahwa test statistic $<$ t tabel yaitu $-1,741<1,9844$ dan -value $>$ a yaitu $0,081>0,05$. Hasil perhitungan 
tersebut menunjukan bahwa customer attitude tidak dapat memediasi antara variabel $E$-wom dengan variabel niat beli.

7. Pengaruh celebrity endorser terhadap niat beli melalui customer attitude

Berdasarkan hasil uji yang digunakan dengan kalkulator sobel menunjukan bahwa test statistic < t tabel yaitu $-1,698<1,9844$ dan p-value > a yaitu 0,089>0,05. Hasil perhitungan tersebut menunjukan bahwa customer attitude tidak dapat memediasi antara variable celebrity endorser dengan variable niat beli.

\subsection{Pembahasan}

E-wom menunjukan bahwa terdapat pengaruh positif terhadap customer attitude. Adanya review yang diberikan customer membantu customer baru membandingkan dengan ayam geprek lainnya. Mulai dari kualitas makanan, kualitas pelayanannya dan harga. Variabel e-wom terhadap niat beli juga menunjukan hasil yang positif. E-wom yang diperoleh dari customer berpengaruh secara signifikan terhadap niat beli. Customer merasa dibantu dengan adanya review dari customer lain mengenai Geprek Bensu secara online.

Celebrity endorser berpengaruh signifikan terhadap customer attitude. Dengan adanya celebrity endorser secara langsung dalam peningkatan customer attitude. Berdasarkan hasil dari kuesioner dan wawancara, customer setuju bahwa ayam geprek Bensu adalah ayam Geprek yang banyak disenangi. Celebrity endorser juga berpengaruh terhadap variable niat beli. Semakin terkenal celebrity membuat customer akan semakin yakin untuk membeli Ayam Geprek Bensu. Hasil dari kuesioner dijelaskan bahwa Ruben Onsu sebagai celebrity pengiklan Geprek Bensu memiliki nama baik di dunia hiburan, selain itu dalam hal penyampaian dapat diterima dengan baik oleh customer dan karakteristiknya dianggap sesuai dengan produk Ayam Geprek Bensu. Hal inilah yang menjadikan Ruben Onsu menjadi celebrity yang mampu mendorong terciptanya customer untuk niat beli,

\section{KESIMPULAN}

Penelitian ini telah mengungkapkan bahwa e-wom dan celebrity endorser memiliki dampak yang signifikan terhadap customer attitude dan niat beli. Namun, customer attitude dalam penelitian ini tidak berpengaruh positif terhadap niat beli. Customer attitude sebagai variabel mediasi juga tidak berpengaruh positif pada variabel e-wom dan selebriti endorser pada variabel niat beli. Penelitian ini masih banyak yang keterbatasan antara lain:

1. Penelitian ini hanya terfokus pada sektor makanan saja.

2. Penelitian ini tidak memperhatikan jenis kelamin dan usia.

3. Diharapkan peneliti selanjutnya apabila ingin melakukan penelitian tentang niat beli sebaiknya lebih universal.

\section{REFERENSI}

Jalilvand, dan Neda. 2011. The Effect of Electronic Word of Mouth On Barnd Image and 
Purchase Intention. Marketing Intelligence and Planning, 30, 461-476.

Muda, M. dan Musa, R., 2014. Celebrity Entrepreneur Endorsement and Advertising Effectiveness. Procedia: Social and Behavioral Sciences, 130, 11-20.

Nelson, Okorie. 2012. Multiple Uses of Celebrities in Brand Promotion: An Experimental Investigation. Journal of comunication, Vol. VII, No. 2, pp. 51-58.

Qian, $\mathrm{Zu}$ dan Teik, Derek Lai. 2015. The Impact of Celebrity Credibility On Consumer's Purchase Intention Toward the Footwear Industry in Malaysia: The Mediating Effect of Attitude Toward Advertisement. Information Management and Business Review, 7(4), 55-63.

Sallam, M.A.A., Nabsiah A.W. 2012. Endorser Credibility Effects on Yemeni Male Consumer's Attitudes towards Advertising, Brand Attitude and Purchase Intention: The Mediating Role of Attitude toward Brand. International Business Research. vol. 5 no. 4: 55-66.

Schiffman, Leon G. dan Kanuk, Leslie L. 2010. Consumer Behavior Tenth Edition. Pearson Education.

Shafiq, R., Raza, I., and Zia-ur-Rehman, M. 2011. Analysis of the factors affecting customers'purchase intention: the mediating role of perceived value. African Journal of Business Management, 5 (20): 8041-8049. 